\title{
OS PROCESSOS DE GESTÃO NO CREAS/SERVIÇO DE PROTEÇÃO E ATENDIMENTO ESPECIALIZADO À MULHER EM SITUAÇÃO DE VIOLÊNCIA DOMÉSTICA E FAMILIAR
}

\author{
Nathalia Germiniani Silva, Juliene Áglio de Oliveira Parrão \\ Centro Universitário "Antônio Eufrásio de Toledo". Curso de Serviço Social, Presidente Prudente - SP. E-mail: \\ nathalia.germiniani@hotmail.com
}

\section{RESUMO}

O presente artigo visa a discussão da importância dos processos de Gestão em meio ao trabalho desenvolvido no CREAS/Serviço de Proteção e Atendimento à Mulher em Situação de Violência Doméstica e Familiar. A Gestão é fundamental para a efetivação de um trabalho social resoluto e qualificado, seus elementos são essenciais para o desenvolvimento das ações executadas pelos profissionais, pois exige um agir baseado em um contínuo diagnóstico social sobre o objeto de intervenção do Serviço. A partir dos processos de Gestão torna-se possível planejar, monitorar e mensurar a qualidade das ações prestadas por meio da avaliação.

Palavras-chave: Gestão. Processos de Gestão. Serviço de Proteção e Atendimento à Mulher. CREAS. Violência doméstica e familiar.

\section{THE MANAGEMENT PROCESSES IN CREAS / SERVICE PROTECTION AND ASSISTANCE TO QUALIFIED WOMAN IN SITUATION OF DOMESTIC VIOLENCE AND FAMILY}

\begin{abstract}
This article aims to discuss the importance of process management in the midst of work on CREAS / Service Protection and Assistance to Women in Situations of Domestic and Family Violence. Management is critical to the realization of a resolute and qualified, its elements are essential for the development of actions performed by professional social work, it requires a continuous act based on social diagnosis on the object of intervention service. From the management processes becomes possible to plan, monitor and measure the quality of actions provided through the evaluation.
\end{abstract}

Keywords: Management. Management processes. Protection Service and Support to Women. CREAS. Domestic and family violence. 


\section{INTRODUÇÃO}

O presente artigo tem por objetivo uma análise e compreensão do Centro de Referência Especializado de Assistência Social(CREAS)/Serviço de Proteção e Atendimento à Mulher em Situação Doméstica e Familiar de Presidente Prudente-SP, no que tange a importância dos processos de Gestão para a execução de um trabalho resoluto e qualificado.

Para tanto, em sua primeira parte, o artigo aborda algumas concepções a respeito do Centro de Referência Especializado de Assistência Social, trazendo seu conceito legislativo, seus principais objetivos e Serviços. Dentre estes, em seu segundo item o estudo possibilita um maior conhecimento e apropriação do Serviço de Proteção e Atendimento Especializado à Mulher em Situação de Violência Doméstica e Familiar do município de Presidente Prudente-SP.

Logo, em ultimo item, o artigo focaliza a importância dos processos de Gestão (planejamento,monitoramento e avaliação) em meio ao trabalho social desenvolvido pela equipe profissional do Serviço, imprescindíveis para a efetivação de um atendimento e acompanhamento baseado na integralidade e qualidade do processo de trabalho desenvolvido pelo CREAS, o qual possue como principal objetivo o rompimento do ciclo de violência vivenciado pelas usuárias. O artigo foi elaborado por meio do método dialético, através de pesquisas bibliográficas e eletrônicas, as quais subsidiaram a discussão acerca da importância dos processos de Gestão.

\section{RESULTADOS}

De acordo com a declaração expressa na Lei № 12.435/2011(Lei Orgânica da Assistencial Social), o Centro de Referência Especializado de Assistência Social- CREAS, constitui-se em uma unidade pública estatal de abrangência municipal ou regional instituída no âmbito do SUAS Sistema Único de Assistência Social(responsável pela descentralização dos serviços socioassistenciais no Brasil). Isto posto, é importante pontuar que segundo o artigo primeiro da LOAS:

Art. 10 A assistência social, direito do cidadão e dever do Estado, é Política de Seguridade Social não contributiva, que provê os mínimos sociais, realizada através de um conjunto integrado de ações de iniciativa pública e da sociedade, para garantir o atendimento às necessidades básicas.

Neste sentido, a política de Assistência Social dispõe diversos serviços com sua determinada tipificação, voltados à Proteção Social Básica, Proteção Social Especial (Média e alta complexidade), à vigilância socioassistencial e à defesa de direitos. Nesta perspectiva, o CREAS se materializa em meio a Proteção Especial de Média Complexidade, tendo como uma de suas 
principais competências, à prestação de serviços especializados e continuados à indivíduos e famílias em situação de risco social instalado, promovendo ações voltadas à potencialização e superação das dificuldades enfrentadas pelos usuários, decorrente da violação de seus direitos,como é o caso de idosos, mulheres, moradores de rua, adolescentes em conflito com a Lei, dentre outros.

De modo geral, a Unidade possui outra competência fundamental, referente a gestão dos processos de trabalho, a qual será melhor discutida nos itens posteriores, no que tange ao serviço de proteção e atendimento à mulher em situação de violência domestica e familiar no município de Presidente Prudente-SP.

O Serviço de Proteção e Atendimento Especializado à Mulher em Situação de Violência possui como principal objetivo de seu trabalho social, a superação da violência vivenciada pelas usuárias em suas diversas formas (física,moral,psicológica, patrimonial e sexual), bem como , o fim da violência de gênero enraizada em nossa sociedade, a qual se caracteriza pela cultura milenar machista, que define o sexo masculino como superior ao sexo feminino.Isto posto, o Serviço busca o fortalecimento e emancipação dessas mulheres, no âmbito emocional,social e político.

Tendo em vista a busca de seus objetivos e seguindo as normativas do SUAS, o CREAS conta com uma equipe técnica e uma de apoio, compostas por profissionais comprometidos com a defesa e garantia dos direitos das mulheres em situação de violência, tendo como principal base de suas ações a Política Nacional de Enfrentamento à Violência contra as Mulheres com plena efetivação da Lei Maria da Penha.

\section{DISCUSSÃO}

Dentre as etapas apresentadas no item anterior e das metodologias utilizadas pelo CREAS, o foco a ser seguido refere-se a uma de suas principais competências, a gestão dos processos de trabalho do Serviço, no que tange ao planejamento, monitoramento e avaliação das ações desenvolvidas na Unidade voltadas à mulher em situação de violência e à seu meio de convivência familiar e comunitária. Para tanto, faz-se importante citar que, segundo as Orientações Técnicas: Centro de Referência Especializado de Assistência Socia (p. 56,2011):

“A gestão dos processos de trabalho da equipe técnica abre um campo favorável para a troca de informações, experiências e conhecimentos,fundamental para qualificação das ações desenvolvidas na Unidade." 
Neste sentido, os profissionais devem estar em um exercício continuo de investigação e estudo, para que assim possam pensar em alternativas qualificadas as necessidades das cidadãs em situação de violência doméstica e familiar.

A gestão dos processos de trabalho do CREAS, implica na elaboração do planejamento de trabalho do Serviço, no monitoramento e na avaliação ações planejadas e executadas pelas equipes. Tais elementos fazem parte das atribuições da coordenadora responsável pela gestão, as quais são: coordenar e executar ações; facilitar os processos de trabalho da equipe; viabilizar as condições técnico-operativas necessárias à prestação dos serviços; definir com a equipe técnica os referenciais teórico-metodológicos, as estratégias e instrumentos a serem utilizados no trabalho com as mulheres e suas famílias; articular os processos de implantação, execução, monitoramento, registro e avaliação das ações, usuários e serviços; realizar reuniões entre os membros internos do Serviço e com a Rede Mulher para discussão dos casos, do trabalho realizado e dos resultados das ações; elaboração de relatórios e outras.

Isto posto, faz-se necessário o destaque e compreensão dos três processos base da gestão do Serviço, bem como, dos indicadores importantes e contribuintes para a construção dos mesmos.

\section{Planejamento}

O planejamento é fundamental para que se tenha uma gestão eficaz e qualificada, pois trata-se de um processo norteador do trabalho social desenvolvido, como o próprio nome já diz, tal processo consiste em planejar as ações a serem desenvolvidas anualmente, mensal e/ou diariamente. Para tanto, faz-se necessário que o gestor do Serviço tenha uma visão crítica da realidade vivenciada pelas usuárias, um olhar para além das demandas imediatas apresentadas, que o possibilite identificar e compreender a complexidade das situações atendidas, desvelar contexto sócio-histórico atrelado ao objeto de intervenção (violência doméstica e familiar) e sobre a forma como é vivenciado por cada uma.

Somente a partir deste diagnóstico social, torna-se possível a elaboração de um planejamento qualificado, composto por respostas profissionais sustentáveis e resolutas às demandas institucionais e sócio-profissionais. Isto posto, coloca-se ainda que, além de nortear o agir dos profissionais do CREAS, o planejamento permite com que a equipe possa refletir a respeito das ações desenvolvidas, e buscar assim, um aprimoramento contínuo das mesmas. 


\section{Monitoramento}

No que tange ao monitoramento, pode-se afirmar que trata-se de uma ferramenta de Gestão tão importante para o trabalho social quanto o planejamento, exigindo o mesmo exercício de reflexão, pois os processos de Gestão possuem uma complementaridade entre si. Segundo as Orientações Técnicas: Centro de Referência de Assistência Social (p.106,2011): “Monitorar e avaliar consiste em um exercício permanente e um compromisso com as repercussões de todo o trabalho social desenvolvido com o conjunto de usuários.".

Diante disto, compreende-se que o monitoramento possui como objetivo o acompanhamento das ações planejadas pelo coordenador responsável pela Gestão e da rotina de trabalho desenvolvida pela equipe, com intuito de qualificar a atenção e proteção prestada pelo Serviço. Isto posto, coloca-se ainda que, a realização do monitoramento pode ocorrer por meio da coleta de informações quantitativas e qualitativas que auxiliam na efetivação do ato de monitorar.

A partir desta compreensão, pode-se citar como exemplo, o acompanhamento dos encaminhamentos realizados pelo Serviço, nos quais as usuárias são acompanhadas pelos profissionais, pessoalmente ou por contato telefônico, a fim de garantir apoio, efetividade da ação e segurança às usuárias em situação de violência doméstica e familiar. Além disso, vale expor que todas as atividades planejadas e executadas são monitoradas pela própria equipe, que busca qualidade e eficácia das ações desenvolvidas.

\section{Avaliação}

O processo de avaliação por sua vez, trata-se de uma dimensão essencial para construção do planejamento de trabalho e para mensurar os resultados das ações executadas pelos profissionais do CREAS. A partir da avaliação torna-se possível identificar, por exemplo, as dificuldades, as soluções, meios para o aprimoramento do trabalho desenvolvido, os resultados positivos, identificar se as metas planejadas foram atingidas ou não, dentre outros. Isto posto, pode-se afirmar que:

[...] o processo de avaliação é elemento constituinte da gestão social democrática e não mero instrumentos ou acessório dela. Avaliar políticas sociais é uma forma concreta e política de enfrentamento de expressões da questão social. Ao produzir conhecimentos, por meio de indicadores podemos problematizar a eficiência, a eficácia e a efetividade das políticas públicas, ou seja, os resultados e impactos produzidos. (ROMERA, 2006 p. 5).

Diante disto, reconhecendo a importância da avaliação como uma forma das formas concretas de enfrentamento à violência doméstica e familiar contra, a equipe do CREAS em 
conjunto com profissionais externos do Serviço construiu como metodologia, um instrumental aplicado em forma de entrevista, o qual compõe-se por quatro dimensões, sociofamiliar, sociorelacional, sócioterritorial e perguntas relacionadas ao serviço.

Tal instrumental é utilizado com as mulheres que vão sendo desligadas do Serviço por superação de violência, possibilitando que os profissionais mensurem a eficiência, eficácia e qualidade do trabalho desenvolvido. Assim através destes indicadores é possível avançar na gestão dos processos de trabalho.

\section{CONCLUSÃO}

Diante do estudo realizado, foi possível reconhecer a notabilidade do CREAS/Serviço de Proteção e Atendimento à Mulher em Situação de Violência Doméstica e Familiar frente ao seu objeto de intervenção, qual seja um fenômeno complexo que exige um agir qualificado e pensado. Além disto, tornou-se perceptível a importância dos processos de Gestão no CREAS, para que o trabalho social realizado pelos profissionais seja eficaz e qualificado, bem como a importância, do papel do coordenador (gestor) em meio a execução dos processos base: planejamento, monitoramento e avaliação.

Tais processos que possuem uma complementaridade entre si, e exigem uma postura crítica,reflexiva e propositiva acerca do objeto de intervenção profissional, através dos processos de gestão torna-se possível a construção de respostas profissionais sustentáveis e resolutas às demandas institucionais e sócio-profissionais.

Logo, os processos de Gestão são imprescindíveis para a efetivação de um atendimento e acompanhamento baseado na integralidade e qualidade do processo de trabalho desenvolvido pelo CREAS, o qual possue como principal objetivo o rompimento do ciclo de violência vivenciado pelas usuárias.

\section{REFERÊNCIAS}

BRASIL. Lei N. 8.742, de 7 de dezembro de 1993. Lei Orgânica de Assistência Social. Disponível em: < http://www.planalto.gov.br/ccivil 03/leis/l8742.htm>. Acesso em 7 de abril de 2014.

BRASIL. Secretaria Nacional de Assistência Social. Ministério do Desenvolvimento Social e Combate à Fome - MDS. Orientações Técnicas: Centro de Referência Especializado de Assistência Social CREAS. Brasília, 2011. Gráfica e Editora Brasil LTDA. Disponível em: < http://www.mds.gov.br/assistenciasocial/secretaria-nacional-de-assistencia-socialsnas/cadernos/orientacoes-tecnicas-centro-de-referencia-especializado-de-assistencia-socialcreas-1/04-caderno-creas-final-dez..pdf>. Acesso: em 20 de abril de 2014. 
BRASIL. Ministério do Desenvolvimento Social e Combate à Fome - MDS. Secretaria Nacional de Assistência Social. Perguntas e Respostas: Centro de Referência especializado de Assistência Social - CREAS. Brasília, 2011. Disponível em: <http://www.mds.gov.br/assistenciasocial/secretarianacional-de-assistencia-social-snas/cartilhas/perguntas-e-respostas-centro-de-referenciaespecializado-de-assistencia-social-creas/03-livreto-perguntas-respostascreas-impressao-2012.pdf>. Acesso em: 15 de abril de 2014.

CREAS. Guia De Procedimentos para o Atendimento Às Mulheres Em Situação De Violência nos Creas. . Serviço de Proteção e Atendimento Especializado à Mulher em Situação de Violência Doméstica e Familiar. 2014.

LUZ, Daniele Aguiar dos Santos. A Dimensão Avaliativa do Processo de Gestão - Serviço de Proteção e Atendimento Especializado À Mulher em Situação de Violência Doméstica e Familiar do Creas de Presidente Prudente - SP, 2013. 